\title{
Adaptabilidade e estabilidade como critérios para seleção de genótipos de girassol
}

\author{
Willyam Stern Porto ${ }^{(1)}$, Claudio Guilherme Portela de Carvalho(2) e Ronald José Barth Pinto(1)
}

(1)Universidade Estadual de Maringá, Dep. de Agronomia, Av. Colombo, no 5.790, CEP 87020-900 Maringá, PR. E-mail: wsporto@yahoo.com.br, rjbp@uem.br (2)Embrapa Soja, Caixa Postal 231, CEP 86001-970 Londrina, PR. E-mail: cportela@cnpso.embrapa.br

\begin{abstract}
Resumo - O objetivo deste trabalho foi comparar critérios para seleção de genótipos de girassol com base na média geral obtida em vários locais e sua decomposição em ambientes favoráveis e desfavoráveis e por meio de outros métodos de análise de adaptabilidade e estabilidade, como os de Eberhart \& Russell, Lin \& Binns, Carneiro e Carvalho et al. Foram analisados dados obtidos entre os anos de 1999 e 2004 na Rede Nacional de Ensaios de Girassol, coordenada pela Embrapa Soja e que conta com a participação de empresas públicas e privadas. Os caracteres avaliados foram rendimento de grãos e de óleo ( $\left.\mathrm{kg} \mathrm{ha}^{-1}\right)$. A análise da decomposição da média geral em médias de ambientes favoráveis e desfavoráveis (método da indicação com base na decomposição da média geral - IDMG) foi o critério mais adequado para a indicação de genótipos. A análise de regressão contribuiu com informações adicionais, indicando a responsividade e previsibilidade dos genótipos diante das mudanças ambientais.
\end{abstract}

Termos para indexação: Helianthus annuus, interação genótipos x ambientes, melhoramento genético, recomendação de cultivares.

\section{Adaptability and stability as selection criteria for sunflower genotypes}

\begin{abstract}
The objective of this work was to compare criteria for selection of sunflower genotypes based on general mean obtained in different locations and its decomposition in favorable and unfavorable environments, as well as other methods of adaptability and stability, such as Eberhart \& Russell, Lin \& Binns, Carneiro and Carvalho et al. Data from 1999 to 2004 of the Official Sunflower Trials Network, coordinated by Embrapa Soja, were analyzed. The characters evaluated were yield of grains and oil $\left(\mathrm{kg} \mathrm{ha}^{-1}\right)$. The analysis of the decomposition of the general mean in favorable and unfavorable environment means (Indication Method - Partitioning of General Mean) was the most suitable for the indication of genotypes. However, the regression analysis contributed with additional information, indicating responsivity and previsibility of the genotypes to environmental changes.
\end{abstract}

Index terms: Helianthus annuus, genotypes x environments interaction, genetic improvement, varieties recommendation.

\section{Introdução}

O girassol (Helianthus annuus L.) apresenta características agronômicas importantes, como maior tolerância à seca, ao frio e ao calor, quando comparado com a maioria das espécies cultivadas no Brasil (Leite, 2005). Entre outros usos, suas sementes podem ser utilizadas para fabricação de ração animal e extração de óleo de alta qualidade para consumo humano ou como matéria-prima para a produção de biodiesel. Devido a essas particularidades e à crescente demanda do setor industrial e comercial, a cultura do girassol é uma importante alternativa econômica em sistemas de rotação, consórcio e sucessão de cultivos nas regiões produtoras de grãos.
A obtenção de informações por meio da pesquisa tem sido decisiva para dar suporte tecnológico ao desenvolvimento da cultura, garantindo melhores produtividades e retornos econômicos competitivos. Entre as várias tecnologias desenvolvidas para a produção de girassol, a escolha adequada de cultivares constitui um dos principais componentes do sistema de produção da cultura. Diante da existência de interação genótipos x ambientes, são necessárias avaliações contínuas, em redes de ensaios, a fim de determinar o comportamento agronômico dos genótipos e sua adaptação às diferentes condições locais.

Atualmente, a avaliação e a seleção de híbridos e variedades de girassol de várias empresas, estão sendo realizadas por meio da Rede de Ensaios de Avaliação 
de Genótipos de Girassol, coordenada pela Embrapa Soja e conduzida por instituições públicas e privadas. Os ensaios têm sido instalados em diferentes locais das Regiões CentroOeste, Nordeste, Sudeste e Sul do país.

A seleção de genótipos de girassol nos ensaios da rede é, normalmente, fundamentada nas médias gerais de rendimento de grãos e de óleo obtidas nos diferentes ambientes (locais e anos) de teste. Entretanto, a consideração de médias em ambientes favoráveis e desfavoráveis pode evidenciar os genótipos com adaptação específica a cada tipo de ambiente, ou a ambos. Esse fato pode ser verificado, também, em outros estudos de adaptabilidade e estabilidade de genótipos (Ramalho, 1993; Cruz \& Regazzi, 1994; Lu'Quez et al., 2002; de la Vega \& Chapman, 2006).

O objetivo deste trabalho foi comparar critérios para seleção de genótipos de girassol com base na média geral obtida em vários locais e sua decomposição em ambientes favoráveis e desfavoráveis e por meio de outros métodos de análise de adaptabilidade e estabilidade.

\section{Material e Métodos}

Os dados analisados foram obtidos da Rede de Ensaios de Avaliação de Genótipos de Girassol, coordenada pelaEmbrapa Soja. Os ensaios foram conduzidos entre 1999 e 2004, em diversos locais dos Estados da Bahia, Goiás, Mato Grosso, Mato Grosso do Sul, Minas Gerais, São Paulo, Paraná, Rio Grande do Sul, Santa Catarina e no Distrito Federal.

Os ensaios foram instalados em agosto/setembro e fevereiro/março, em delineamento experimental de blocos completos casualizados, com quatro repetições. Cada parcela foi constituída de quatro linhas de $6 \mathrm{~m}$ de comprimento, espaçadas de 0,7 a $0,9 \mathrm{~m}$. Na colheita, as duas linhas externas e $0,5 \mathrm{~m}$ de cada extremidade das linhas centrais foram descartadas como bordaduras, obtendo-se uma área útil na parcela de 7 a $9 \mathrm{~m}^{2}$, dependendo do espaçamento adotado. Tratos culturais, como adubação, capina e controle fitossanitário foram realizados objetivando um bom desenvolvimento das plantas.

Os genótipos testados foram híbridos (simples e triplos) e variedades de polinização aberta (populações) das empresas Advanta, Cati, Dow AgroSciences, Embrapa Soja, La Tijereta e Helianthus do Brasil. Cada grupo de genótipos foi avaliado na rede durante dois anos em ensaio final de primeiro ano (1o ano de avaliação) e em ensaio final de segundo ano ( 2 o ano de avaliação). Foram utilizados como testemunhas os híbridos comerciais M 734 (Dow AgroSciences) e AGROBEL 960 (La Tijereta). Os caracteres avaliados foram rendimento de grãos e de óleo $\left(\mathrm{kg} \mathrm{ha}^{-1}\right)$.
Nos ensaios finais de primeiro ano, instalados em agosto/ setembro, os locais avaliados e as respectivas instituições/ empresas responsáveis foram Campo Mourão (Cooperativa Mista Agropecuária do Brasil) e Londrina (Embrapa Soja), PR; Cruz Alta (Universidade de Cruz Alta) e Passo Fundo (Universidade de Passo Fundo), RS e Campinas (Instituto Agronômico de Campinas) e Manduri (Coordenadoria de Assistência Técnica Integral), SP. Nos ensaios finais de segundo ano, os locais (instituições/empresas) foram Curitiba (Pontifícia Universidade Católica do Paraná), Londrina (Embrapa Soja), Campo Mourão (Cooperativa Agroindustrial Mourãoense), Maringá (Universidade Estadual de Maringá), PR; Rio do Sul (Escola Agrotécnica Federal de Rio do Sul), SC; Ibirubá (Cooperativa Agrícola Mista de General Osório Ltda.), Ijuí (Cooperativa Regional Tritícola Serrana Ltda.) e Três de Maio (Cooperativa Agropecuária Alto do Uruguai Ltda.), RS; Araras (Universidade Federal de São Carlos), Campinas (Instituto Agronômico de Campinas) e Manduri (Coordenadoria de Assistência Técnica Integral), SP e Irecê (Empresa Baiana de Pesquisa Agrícola S.A.), BA.

Nos ensaios finais de primeiro ano, instalados em fevereiro/março, os locais avaliados e as respectivas empresas/instituições foram Jataí (Universidade Federal de Goiás), GO; Uberlândia (Monsanto), MG; Campo Novo do Parecis (propriedade rural) e Nova Mutum (Universidade de Várzea Grande) MT e Cravinhos (Dow AgroSciences), Jardinópolis (Dow AgroSciences) e Manduri (Coordenadoria de Assistência Técnica Integral), SP. Os ensaios finais de segundo ano foram instalados em Planaltina (Embrapa Cerrados), DF; Jataí (Universidade Federal de Goiás) e Rio Verde (Escola Superior de Ciências Agrárias de Rio Verde), GO; Uberlândia (Monsanto), MG; Campo Novo do Parecis (propriedade rural), Jaciara, Juscimeira e Primavera do Leste (Universidade Federal do Mato Grosso) e Nova Mutum (Universidade de Várzea Grande), MT; Chapadão do Sul (Fundação Chapadão) e Dourados (Embrapa Agropecuária Oeste), MS e Cravinhos (DOW AgroSciences) e Manduri e São Manuel (Coordenadoria de Assistência Técnica Integral), SP.

Foram realizadas as análises de variância para os dados de rendimento de grãos e óleo, aferidos em cada local, ano e época de semeadura. Como nem sempre os locais de teste nos ensaios finais de primeiro ano foram os mesmos dos ensaios finais de segundo ano, foi realizada análise conjunta de ambientes (local e ano específicos) para cada época de semeadura e grupo de genótipos. Para isto, verificou-se a existência de homogeneidade das variâncias residuais obtidas nas análises individuais sempre que a razão 
entre o maior e o menor quadrado médio residual foi inferior a sete (Pimentel-Gomes, 1985). Além disso, alguns ensaios não foram considerados nas análises de variância conjuntas por terem apresentado coeficientes de variação superiores a 20\% (Pimentel-Gomes, 1985) para rendimento de grãos, ou por terem sido perdidos pelo ataque de pássaros, seca ou doenças como mancha-de-alternária.

Na seleção dos genótipos, foram adotados três critérios: média geral obtida nos diferentes ambientes de teste; decomposição da média geral em ambientes favoráveis e desfavoráveis, e outros métodos de análise de adaptabilidade e estabilidade.

$\mathrm{Na}$ análise da média geral, foi realizado o teste de Duncan, a 5\% de probabilidade, para verificar se houve diferenças significativas entre os genótipos. Posteriormente, a média de cada genótipo foi comparada com a média das testemunhas, e os genótipos que superaram a média das testemunhas foram selecionados.

Foi proposta, também, neste estudo, a decomposição da média geral em médias de ambientes favoráveis e desfavoráveis (método da indicação com base na decomposição da média geral - IDMG), e estas foram comparadas às médias das testemunhas nesses dois tipos de ambientes. Quando a média de um genótipo é superior à média das testemunhas nos ambientes favoráveis, mas não nos desfavoráveis, este genótipo pode ser indicado para ambientes favoráveis; o mesmo ocorre para os ambientes desfavoráveis. Se a média for superior em ambos os ambientes, a indicação é geral.

Além do método IDMG outros estudos de adaptabilidade e estabilidade dos genótipos foram feitos usando os métodos de Eberhart \& Russell (1966), Lin \& Binns (1988) e Carvalho et al. (2002). Realizou-se, também, a decomposição do parâmetro Pi de Lin \& Binns (1988) em Pif (ambientes favoráveis) e Pid (ambientes desfavoráveis) como sugerido por Carneiro (1998). No método de Carvalho et al. (2002), é calculado o número de genótipos, nos ambientes desfavoráveis $\left(\mathrm{X}_{\mathrm{d}}\right)$ e favoráveis $\left(\mathrm{X}_{\mathrm{f}}\right)$, com médias maiores que a média de um determinado genótipo (Li). Quando a diferença (D) entre $X_{d}$ e $X_{f}$ for igual ou superior a $1 / 3$ do número $(N)$ de linhagens avaliadas, inferese que Li apresenta adaptabilidade a ambientes favoráveis. Se $\mathrm{D} \leq-1 / 3 \mathrm{~N}$, Li tem adaptabilidade a ambientes desfavoráveis e se $-1 / 3 \mathrm{~N}<\mathrm{D}<1 / 3 \mathrm{~N}$, Li mostra adaptabilidade geral. Neste estudo, para simplificação, foi efetuada a classificação dos genótipos e calculada a diferença (D) entre os postos obtidos nos ambientes favoráveis e desfavoráveis para cada genótipo. A classificação substituiu o cálculo de $\mathrm{X}_{\mathrm{d}} \mathrm{e} \mathrm{X}_{\mathrm{f}}$.

A decomposição da média geral e as análises, segundo os métodos de Carneiro (1998) e Carvalho et al. (2002), não foram realizadas quando o número de ambientes desfavoráveis ou favoráveis foi igual ou inferior a dois. Todas as análises estatísticas foram realizadas por meio do programa computacional Genes (Cruz, 2001).

\section{Resultados e Discussão}

Nas análises de variância conjuntas para rendimento de grãos e de óleo, observaram-se diferenças significativas na interação genótipos $\mathrm{x}$ ambientes, indicando mudança no desempenho dos genótipos de girassol nos diversos ambientes avaliados e evidenciando a importância de estudos dos componentes de rendimento em ambientes específicos (Tabela 1), como descrito por Allard \& Bradshaw (1964). A presença de interação

Tabela 1. Análises de variância conjuntas para rendimento de grãos e óleo ( $\left.\mathrm{kg} \mathrm{ha}^{-1}\right)$ de genótipos de girassol, avaliados na Rede Nacional de Ensaios de Girassol, no período de 1999 e 2004.

\begin{tabular}{|c|c|c|c|c|c|c|c|c|}
\hline \multirow[t]{2}{*}{ Variável } & \multicolumn{4}{|c|}{ Safra $^{(1)}$} & \multicolumn{4}{|c|}{ Safra $^{(2)}$} \\
\hline & $2000 / 2001$ & $2001 / 2002$ & $2002 / 2003$ & $2003 / 2004$ & 2001 & 2002 & 2003 & 2004 \\
\hline & \multicolumn{8}{|c|}{ Rendimento de grãos } \\
\hline $\mathrm{QMGA}^{(3)}$ & $348.018 * *$ & $337.704^{* *}$ & $219.032 * *$ & $408.164 * *$ & $211.209 * *$ & $371.927 * *$ & $326.407 * *$ & $178.296 * *$ \\
\hline $\mathrm{CV}(\%)$ & 14,49 & 13,95 & 13,84 & 15,50 & 12,44 & 11,83 & 12,18 & 14,33 \\
\hline \multirow[t]{2}{*}{ Média (4) } & 1.832 & 1.871 & 1.489 & 1.800 & 1.864 & 1.702 & 1.901 & 2.055 \\
\hline & \multicolumn{8}{|c|}{ Rendimento de óleo } \\
\hline QMGA & $70.347 * *$ & $75.493 * *$ & $42.310 * *$ & $64.739 * *$ & $51.440 * *$ & $50.324 * *$ & $57.947 * *$ & $34.646^{* *}$ \\
\hline CV $(\%)$ & 16,93 & 14,91 & 15,84 & 16,85 & 13,41 & 12,23 & 13,75 & 14,51 \\
\hline Média & 807 & 798 & 523 & 718 & 819 & 663 & 751 & 824 \\
\hline
\end{tabular}

(1)Avaliações realizadas no ano/safra 2000/2001 (semeadura em agosto/setembro) incluem os dados experimentais obtidos no ensaio final de primeiro ano (1999/2000) e ensaio final de segundo ano (2000/2001), com procedimento similar para os demais anos de avaliação. (2) Avaliações realizadas no ano/safra 2001 (semeadura em fevereiro/março) inclui os dados experimentais obtidos no ensaio final de primeiro ano (2000) e ensaio final de segundo ano (2001), com procedimento similar para os demais anos de avaliação. (3) Quadrado médio da interação genótipos x ambientes. (4) Média geral, em $\mathrm{kg} \mathrm{ha}^{-1}$. **Significativo a $1 \%$ de probabilidade, pelo teste $\mathrm{F}$. 
genótipos x ambientes em girassol foi, também, encontrada por Lu'Quez et al. (2002) e de la Vega \& Chapman (2006). Os coeficientes de variação (CV) variaram, nesse estudo, de 11,83 a 16,93\%, o que sugere uma precisão experimental satisfatória, segundo a classificação de Pimentel-Gomes (1985). Na maioria dos anos avaliados, as médias dos experimentos foram superiores à média das lavouras, que é de $1.500 \mathrm{~kg} \mathrm{ha}^{-1}$, segundo dados da Conab (2005).

Apesar de os valores de CV encontrarem-se em intervalos aceitáveis, o teste de Duncan, a 5\% de probabilidade, somente detectou diferenças significativas entre os genótipos quando houve grande diferença entre suas médias. Em algumas análises, quase todos os genótipos não diferiram entre si quanto aos dois caracteres avaliados. Contudo, verificando-se a classificação (posto) dos genótipos em cada ambiente, foi possível observar razoáveis diferenças entre eles. Na safra 2003/2004, por exemplo, o genótipo ACA 884 revelou bons desempenhos para rendimento de grãos em todos os ambientes avaliados (Tabela 2). Por sua vez, o genótipo Catissol na maioria dos ambientes ocupou os últimos postos. Com base nesses resultados, a análise de componentes de rendimento de girassol, para as duas épocas de semeadura, foi efetuada por meio da comparação do desempenho de cada genótipo em relação à média das testemunhas dos ensaios. Esse critério foi mais rigoroso na discriminação de genótipos que o teste de Duncan, uma vez que reduziu o número de genótipos selecionados. Esse é o critério adotado pelo Ministério da Agricultura, Pecuária e Abastecimento para o registro de novas cultivares de soja, trigo e feijão (Brasil, 2006). Entretanto, quanto ao girassol ainda não foi estabelecido nenhum critério.

A decomposição da média geral em ambientes favoráveis e desfavoráveis (método da IDMG) propiciou informações sobre a qual tipo de ambiente específico, determinado genótipo pode ser indicado (Tabelas 3 e 4). Mesmo com média geral superior à das testemunhas quanto a rendimento de grãos, pelo método da IDMG, observou-se, por exemplo, que os genótipos EM 677008 (2000/2001) e GV 26048 (2001/2002) foram indicados para ambientes favoráveis. Da mesma forma, quanto ao rendimento de óleo, os genótipos GV 26048 (2001/ 2002), A 972 (2003/2004) e AG 966 e GH 12 (2001) foram, também, indicados para ambientes favoráveis. A decomposição da média possibilitou a detecção de genótipos que não haviam apresentado média geral superior à das testemunhas, mas que se destacaram em ambientes específicos. O genótipo ACA 885 foi indicado para ambientes desfavoráveis quanto às características rendimento de grãos e de óleo, tanto em 2003/2004 quanto em 2003, apesar de sua média geral ter sido inferior à das testemunhas para as duas épocas de semeadura. Por sua vez, a indicação aos ambientes favoráveis foi obtida para os genótipos CF 17 e Milênio (2001), para rendimento de grãos e GV 26043, CF 17 e VDH 93 (2001), quanto a rendimento de óleo.

Tabela 2. Média geral e ranqueamento (posto) de genótipos de girassol avaliados no ensaio final de primeiro ano/safra (2002/ $2003)^{(1)}$ e ensaio final de segundo ano/safra $(2003 / 2004)^{(2)}$, quanto ao rendimento de grãos $\left(\mathrm{kg} \mathrm{ha}^{-1}\right)$.

\begin{tabular}{|c|c|c|c|c|c|c|c|c|c|c|}
\hline \multirow[t]{2}{*}{ Genótipo } & \multirow[t]{2}{*}{ Média $^{(3)}$} & \multicolumn{9}{|c|}{ Ranqueamento } \\
\hline & & Manduri & Londrina & Passo Fundo & C. Mourão 2 & Campinas & Ibirubá & Curitiba & Cruz Alta & C. Mourão 1 \\
\hline ACA 884 & $2.225 \mathrm{a}$ & 1 & 3 & 3 & 1 & 1 & 5 & 2 & 2 & 2 \\
\hline M $734(\mathrm{~T})$ & $2.146 \mathrm{ab}$ & 2 & 5 & 2 & 9 & 3 & 6 & 1 & 1 & 3 \\
\hline ACA 885 & $1.827 \mathrm{ab}$ & 10 & 7 & 1 & 2 & 6 & 4 & 11 & 3 & 10 \\
\hline A 972 & $1.808 \mathrm{ab}$ & 3 & 1 & 10 & 3 & 8 & 2 & 8 & 5 & 1 \\
\hline ACA 872 & $1.791 \mathrm{ab}$ & 11 & 4 & 4 & 6 & 7 & 1 & 9 & 6 & 8 \\
\hline V 10034 & $1.764 \mathrm{ab}$ & 4 & 2 & 5 & 10 & 9 & 3 & 7 & 7 & 7 \\
\hline AG $960(\mathrm{~T})$ & $1.757 \mathrm{ab}$ & 7 & 8 & 6 & 4 & 4 & 7 & 4 & 11 & 5 \\
\hline Helio 358 & $1.684 \mathrm{ab}$ & 5 & 10 & 7 & 11 & 2 & 8 & 5 & 10 & 4 \\
\hline Catissol & $1.661 \mathrm{ab}$ & 6 & 11 & 8 & 8 & 5 & 9 & 6 & 8 & 6 \\
\hline V 80198 & $1.572 \mathrm{~b}$ & 8 & 6 & 9 & 5 & 10 & 10 & 10 & 4 & 11 \\
\hline Nutrissol & $1.563 \mathrm{~b}$ & 9 & 9 & 11 & 7 & 11 & 11 & 3 & 9 & 9 \\
\hline Prod. geral & 1.800 & 1.209 & 1.523 & 1.564 & 1.577 & 1.599 & 1.821 & 2.022 & 2.354 & 2.527 \\
\hline Testemunhas & 1.951 & - & - & - & - & - & - & - & - & - \\
\hline Prod. máxima & & 1.577 & 1.721 & 2.408 & 2.055 & 2.390 & 2.087 & 2.663 & 3.516 & 2.939 \\
\hline Prod. mínima & & 800 & 1.270 & 723 & 966 & 1.165 & 1.560 & 1.578 & 1.868 & 2.069 \\
\hline
\end{tabular}

${ }^{(1)}$ Os locais avaliados no ensaio final de primeiro ano/safra (2002/2003) foram Cruz Alta e Passo Fundo, RS e Campo Mourão 1, PR. (2) Os locais avaliados no ensaio final de segundo ano foram Ibirubá, RS, Campo Mourão 2, Curitiba, Londrina, PR e Campinas e Manduri, SP. (3)Médias seguidas da mesma letra não diferem entre si pelo teste de Duncan, a $5 \%$ de probabilidade. 
Além da comparação entre a média dos genótipos e a média das testemunhas nos ambientes favoráveis e desfavoráveis, critérios como a realização de testes de significância, poderiam ter sido utilizados. Entretanto estes testes podem apresentar a desvantagem de permitir que um mesmo genótipo esteja associado a mais de um grupo. Outro critério que poderia ser utilizado é a comparação em relação a melhor testemunha ou a média geral. Nesse caso, a seleção seria mais ou menos rigorosa, respectivamente, pois ter-seia menor ou maior número de genótipos com indicação geral ou específica em diferentes ambientes.

É importante salientar que, neste estudo, foi realizada comparação entre híbridos simples, triplos e variedades de polinização aberta, o que pode ter influenciado a estabilidade e adaptabilidade dos genótipos, porém não a comparação de métodos de seleção.

Tabela 3. Decomposição da média geral de genótipos de girassol em ambientes favoráveis e desfavoráveis quanto aos caracteres rendimento de grãos e óleo, nos ensaios instalados em agosto/setembro, entre os anos/safras 2000/2001 e 2003/2004.

\begin{tabular}{|c|c|c|c|c|c|c|}
\hline \multirow[t]{2}{*}{ Genótipo } & \multicolumn{3}{|c|}{ Rendimento de grãos $\left(\mathrm{kg} \mathrm{ha}^{-1}\right)$} & \multicolumn{3}{|c|}{ Rendimento de óleo $\left(\mathrm{kg} \mathrm{ha}^{-1}\right)$} \\
\hline & MG & MD & MF & MG & MD & MF \\
\hline & \multicolumn{6}{|c|}{$2000 / 2001^{(1)}$} \\
\hline AG 930 & 2.036 & 1.405 & 2.667 & 873 & 554 & 1.033 \\
\hline AG $960(\mathrm{~T})$ & 2.047 & 1.596 & 2.497 & 937 & 643 & 1.084 \\
\hline AG 966 & 1.769 & 1.224 & 2.315 & 853 & 511 & 1.023 \\
\hline Catissol & 1.502 & 1.026 & 1.979 & 637 & 419 & 746 \\
\hline DK 4030 & 1.929 & 1.562 & 2.296 & 905 & 575 & 1.070 \\
\hline EM 677008 & 2.189 & 1.556 & 2.821 & 862 & 495 & 1.046 \\
\hline HT 01 & 1.662 & 1.440 & 1.885 & 744 & 590 & 821 \\
\hline HT 09 & 1.554 & 1.271 & 1.837 & 687 & 551 & 755 \\
\hline HT 14 & 1.598 & 1.248 & 1.948 & 718 & 486 & 834 \\
\hline M 734 (T) & 2.186 & 1.778 & 2.595 & 879 & 510 & 1.064 \\
\hline SE 04 & 1.680 & 1.324 & 2.036 & 785 & 537 & 908 \\
\hline Prod. geral & 1.832 & 1.403 & 2.261 & 908 & 576 & 1.074 \\
\hline \multirow[t]{2}{*}{ Testemunhas } & 2.117 & 1.687 & 2.546 & 807 & 534 & 944 \\
\hline & \multicolumn{6}{|c|}{$2001 / 2002$} \\
\hline AG $960(\mathrm{~T})$ & 1.817 & 1.453 & 2.035 & 790 & 636 & 882 \\
\hline CF 13 & 1.659 & 1.331 & 1.856 & 752 & 598 & 845 \\
\hline CF 17 & 1.922 & 1.378 & 2.248 & 814 & 547 & 974 \\
\hline Exp 792 & 1.762 & 1.248 & 2.070 & 777 & 538 & 920 \\
\hline GV 26043 & 1.688 & 1.167 & 2.001 & 718 & 482 & 859 \\
\hline GV 26048 & 2.150 & 1.557 & 2.506 & 872 & 611 & 1.029 \\
\hline M 734 (T) & 2.248 & 1.753 & 2.545 & 918 & 708 & 1.044 \\
\hline VDH 488 & 1.657 & 1.140 & 1.968 & 744 & 508 & 886 \\
\hline VDH 93 & 1.939 & 1.365 & 2.284 & 801 & 538 & 959 \\
\hline Prod. geral & 1.871 & 1.377 & 2.168 & 798 & 574 & 933 \\
\hline \multirow[t]{2}{*}{ Testemunhas } & 2.032 & 1.603 & 2.290 & 854 & 672 & 963 \\
\hline & \multicolumn{6}{|c|}{$2003 / 2004$} \\
\hline A 972 & 1.808 & 1.412 & 2.302 & 773 & 586 & 1.008 \\
\hline ACA 872 & 1.791 & 1.503 & 2.150 & 750 & 616 & 918 \\
\hline ACA 884 & 2.225 & 1.998 & 2.509 & 852 & 744 & 987 \\
\hline Catissol & 1.661 & 1.356 & 2.041 & 655 & 519 & 826 \\
\hline Helio 358 & 1.684 & 1.352 & 2.099 & 736 & 572 & 942 \\
\hline M 734 (T) & 2.146 & 1.725 & 2.673 & 786 & 632 & 979 \\
\hline Nutrissol & 1.563 & 1.152 & 2.077 & 586 & 413 & 803 \\
\hline V 10034 & 1.764 & 1.437 & 2.172 & 651 & 501 & 837 \\
\hline V 80198 & 1.572 & 1.307 & 1.903 & 647 & 514 & 812 \\
\hline Prod. geral & 1.800 & 1.495 & 2.181 & 718 & 579 & 892 \\
\hline Testemunhas & 1.951 & 1.627 & 2.357 & 758 & 626 & 924 \\
\hline
\end{tabular}

(1) Avaliações realizadas em 2000/2001 incluem os dados experimentais obtidos no ensaio final de primeiro ano (1999/2000) e ensaio final de segundo ano (2000/2001), com procedimento similar para os demais anos de avaliação; a decomposição da média geral não foi realizada para o ano 2002/2003, pois apresentou número de ambientes favoráveis ou desfavoráveis igual ou inferior a dois; MG: média geral; MD: média nos ambientes desfavoráveis; MF: média nos ambientes favoráveis. 
As correlações de Pearson entre média geral (MG) e média nos ambientes desfavoráveis (MD) e entre média geral e média nos ambientes favoráveis (MF) dos dois caracteres avaliados em todos os anos foram, na grande maioria dos casos, superiores a 0,80 , exceto em alguns casos, como, por exemplo, a correlação para rendimento de óleo em 2000/2001 ( $\mathrm{r}=0,55)$. Isso indicou que a consideração de ambientes favoráveis e desfavoráveis pode levar à detecção de genótipos com adaptação específica a estes dois tipos de ambientes, como verificado no método da IDMG.
Ao comparar MG, MD e MF com os parâmetros Pi, Pid e Pif, respectivamente, verificou-se correlação acima de 0,90 , na maioria dos casos, quanto aos dois caracteres avaliados, entre 1999 e 2004. Estes resultados indicam que as médias dos genótipos apresentaram tendência a refletir sua adaptabilidade, como definida por Lin \& Binns (1988) e Carneiro (1998). Carvalho et al. (2002), analisando linhagens de soja, e Carvalho et al. (2003), avaliando híbridos de cacaueiro, também obtiveram correlação negativa próxima à unidade, entre estes parâmetros. Neste estudo, as médias foram analisadas

Tabela 4. Decomposição da média geral de genótipos de girassol em ambientes favoráveis e desfavoráveis quanto aos caracteres rendimento de grãos e óleo $\left(\mathrm{kg} \mathrm{ha}^{-1}\right)$, nos ensaios instalados em agosto/setembro, entre os anos/safras 2001 e 2004.

\begin{tabular}{|c|c|c|c|c|c|c|}
\hline \multirow[t]{2}{*}{ Genótipo } & \multicolumn{3}{|c|}{ Rendimento de grãos $\left(\mathrm{kg} \mathrm{ha}^{-1}\right)$} & \multicolumn{3}{|c|}{ Rendimento de óleo $\left(\mathrm{kg} \mathrm{ha}^{-1}\right)$} \\
\hline & MG & MD & MF & $\mathrm{MG}$ & MD & $\mathrm{MF}$ \\
\hline & \multicolumn{6}{|c|}{$2001^{(1)}$} \\
\hline AG 966 & 1.859 & 1.500 & 2.338 & 860 & 683 & 1.096 \\
\hline CF 13 & 1.896 & 1.526 & 2.391 & 901 & 724 & 1.138 \\
\hline CF 17 & 1.951 & 1.453 & 2.614 & 791 & 603 & 1.042 \\
\hline DK 4030 & 1.886 & 1.590 & 2.279 & 865 & 747 & 1.021 \\
\hline GH 12 & 1.882 & 1.442 & 2.468 & 855 & 667 & 1.106 \\
\hline GV 26043 & 1.853 & 1.517 & 2.301 & 812 & 676 & 993 \\
\hline HT 3 & 1.401 & 1.144 & 1.744 & 614 & 497 & 770 \\
\hline M $734(\mathrm{~T})$ & 2.046 & 1.722 & 2.479 & 821 & 716 & 961 \\
\hline MILENIO & 2.028 & 1.573 & 2.635 & 894 & 719 & 1.128 \\
\hline VDH 488 & 1.831 & 1.583 & 2.163 & 820 & 726 & 946 \\
\hline VDH 93 & 1.867 & 1.486 & 2.376 & 780 & 623 & 988 \\
\hline Prod. geral & 1.864 & 1.503 & 2.344 & 819 & 671 & 1.017 \\
\hline \multirow{2}{*}{ Testemunhas } & 2.046 & 1.722 & 2.479 & 821 & 716 & 961 \\
\hline & \multicolumn{6}{|c|}{2003} \\
\hline ACA 872 & 1.951 & 1.668 & 2.235 & 791 & 662 & 986 \\
\hline ACA 884 & 1.988 & 1.727 & 2.249 & 759 & 683 & 872 \\
\hline ACA 885 & 1.911 & 1.704 & 2.118 & 747 & 669 & 866 \\
\hline AG $960(\mathrm{~T})$ & 1.819 & 1.447 & 2.191 & 737 & 602 & 939 \\
\hline Catissol & 1.633 & 1.426 & 1.840 & 632 & 511 & 815 \\
\hline Helio 250 & 1.919 & 1.569 & 2.269 & 827 & 680 & 1.049 \\
\hline Helio 251 & 2.044 & 1.691 & 2.396 & 776 & 657 & 956 \\
\hline M $734(\mathrm{~T})$ & 2.152 & 1.766 & 2.539 & 809 & 682 & 999 \\
\hline V 80198 & 1.856 & 1.567 & 2.144 & 745 & 628 & 921 \\
\hline V 90064 & 1.738 & 1.377 & 2.100 & 686 & 555 & 882 \\
\hline Prod. geral & 1.901 & 1.594 & 2.208 & 751 & 633 & 928 \\
\hline \multirow[t]{2}{*}{ Testemunhas } & 1.986 & 1.607 & 2.365 & 773 & 642 & 969 \\
\hline & \multicolumn{6}{|c|}{2004} \\
\hline AG $960(\mathrm{~T})$ & 2.198 & 1.860 & 2.620 & 930 & 787 & 1.217 \\
\hline EMB 122 & 1.755 & 1.471 & 2.110 & 697 & 598 & 893 \\
\hline Helio 358 & 1.986 & 1.641 & 2.418 & 885 & 723 & 1.207 \\
\hline M $734(\mathrm{~T})$ & 2.381 & 1.880 & 3.007 & 903 & 748 & 1.214 \\
\hline Multissol & 1.939 & 1.584 & 2.382 & 735 & 613 & 977 \\
\hline V 10034 & 2.070 & 1.812 & 2.394 & 796 & 651 & 1.086 \\
\hline Prod. geral & 2.055 & 1.708 & 2.488 & 824 & 687 & 1.099 \\
\hline Testemunhas & 2.289 & 1.870 & 2.813 & 917 & 767 & 1.216 \\
\hline
\end{tabular}

(1) Avaliações realizadas em 2001 incluem os dados experimentais obtidos no ensaio final de primeiro ano (2000) e ensaio final de segundo ano (2001); foi procedido de modo similar para os demais anos de avaliação; a decomposição da média geral não foi realizada em 2002, pois apresentou número de ambientes favoráveis ou desfavoráveis igual ou inferior a dois; MG: média geral; MD: média nos ambientes desfavoráveis; MF: média nos ambientes favoráveis. 
ao invés dos valores de $\mathrm{Pi}$, pois esta substituição tem a vantagem de simplificar as análises de adaptabilidade e estabilidade, permitindo ainda a realização de testes de significância.

Assim como a decomposição da média geral, os métodos de Carvalho et al. (2002) ofereceram informações para qual tipo de ambiente um genótipo pode ser indicado (Tabelas 5 e 6). Contudo, esses métodos não evidenciaram genótipos que, apesar de terem apresentado desempenhos inferiores à média geral, se destacaram em ambientes específicos, como os genótipos ACA 885 (2003/2004 e 2003), CF 17 (2001) e Milênio (2001), quanto a rendimento de grãos e ACA 885 (2003/ 2004 e 2003), GV 26043, CF 17 e VDH 93 (2001), quanto a rendimento de óleo (Tabelas 3 e 4).

As análises segundo o método de Carvalho et al. (2002) foram concordantes com o método de Eberhart \& Russell (1966) em 67,25 e 63,79\%, para rendimento de grãos e de óleo, respectivamente, quando considerado o índice $1 / 3 \mathrm{~N}$. Resultados semelhantes foram obtidos por Carvalho et al. (2002), avaliando linhagens de soja, sendo verificada similaridade de 72,1, 82 e 74,5\%, para os grupos de maturação $\mathrm{L}, \mathrm{M}$ e $\mathrm{N}$, respectivamente. Neste trabalho, quando houve divergência entre eles, verificou-se que, para alguns genótipos, o método de Carvalho et al. (2002) foi similar ao IDMG, ao passo que, para outros genótipos, foi observada similaridade com o método de Eberhart \& Russell (1966).

Uma crítica ao método de Carvalho et al. (2002) é que um genótipo pode ter média geral acima das testemunhas e apresentar adaptabilidade geral (desempenhos similares em MD e MF), mas ter desempenho inferior ao das testemunhas em determinado tipo de ambiente. Isto pode ser verificado no ano 2001/ 2002, para rendimento de grãos do genótipo GV 26048 (Tabela 5). Outra limitação do método é quanto à possibilidade de dois genótipos apresentarem classificações diferentes, mesmo que a diferença entre suas médias, em valores absolutos, seja pequena. Contudo, a utilização do índice de $1 / 3 \mathrm{~N}$ forneceu consistência ao método. Isto pode ser verificado pela sua razoável similaridade com o método de Eberhart \& Russell (1966). Outros valores, como $1 / 4 \mathrm{~N}$, poderiam ter sido utilizados, entretanto foi verificado previamente que este não ocasionaria mudanças na avaliação da adaptabilidade. A similaridade entre os índices $1 / 3 \mathrm{~N}$ e $1 / 4 \mathrm{~N}$ foi de $90,87 \%$. Contudo, o reduzido número de genótipos avaliados pode ter contribuído para essa porcentagem.

Resultados obtidos pelo método de Eberhart \& Russell (1966) indicam que o genótipo Milênio, no ano 2001, para rendimento de óleo, apresentou adaptabilidade aos ambientes favoráveis $\left(\beta_{1}>1\right)$ mas, pela análise da IDMG, percebe-se que a média, em ambos os ambientes, foi superior à média das testemunhas, sugerindo indicação geral (Tabelas 4 e 6). Resultados semelhantes foram observados para outros genótipos avaliados.

Apesar da melhor adequação do método da IDMG para indicação de genótipos a ambientes distintos ou gerais, as análises dos coeficientes e das variâncias dos desvios da regressão foram importantes, pois contribuíram com informações adicionais. Um genótipo pode, por exemplo, ter médias superiores à média das testemunhas em ambientes favoráveis e desfavoráveis,

Tabela 5. Decomposição da média geral e parâmetros de adaptabilidade e estabilidade do caráter rendimento de grãos $\left(\mathrm{kg}_{\mathrm{g}}\right.$ ha $\left.{ }^{-1}\right)$ de genótipos de girassol, avaliados no ano/safra 2001/2002, com base no método de Carvalho et al. (2002)(1).

\begin{tabular}{|c|c|c|c|c|c|c|c|}
\hline \multirow[t]{2}{*}{ Genótipo } & \multicolumn{7}{|c|}{ Rendimento de grãos $\left(\mathrm{kg} \mathrm{ha}^{-1}\right)$} \\
\hline & MG & $\mathrm{MD}$ & RMD & $\mathrm{MF}$ & RMF & RMD - RMF & Adapt. $(1 / 3 \mathrm{~N}=3)$ \\
\hline AG $960(\mathrm{~T})$ & 1.817 & 1.453 & 3 & 2.035 & 6 & -3 & Desfavorável \\
\hline CF 13 & 1.659 & 1.331 & 6 & 1.856 & 9 & -3 & Desfavorável \\
\hline CF 17 & 1.922 & 1.378 & 4 & 2.248 & 4 & 0 & Geral \\
\hline Exp 792 & 1.762 & 1.248 & 7 & 2.070 & 5 & 2 & Geral \\
\hline GV 26043 & 1.688 & 1.167 & 8 & 2.001 & 7 & 1 & Geral \\
\hline GV 26048 & 2.150 & 1.557 & 2 & 2.506 & 2 & 0 & Geral \\
\hline M $734(\mathrm{~T})$ & 2.248 & 1.753 & 1 & 2.545 & 1 & 0 & Geral \\
\hline VDH 488 & 1.657 & 1.140 & 9 & 1.968 & 8 & 1 & Geral \\
\hline VDH 93 & 1.939 & 1.365 & 5 & 2.284 & 3 & 2 & Geral \\
\hline Produtividade geral & 1.871 & 1.377 & - & 2.168 & - & - & - \\
\hline Testemunhas & 2.032 & 1.603 & - & 2.290 & - & - & - \\
\hline
\end{tabular}

(1)MG: média geral; MD: média nos ambientes desfavoráveis; RMD: ranqueamento do genótipo com base na MD; MF: média nos ambientes favoráveis; RMF: ranqueamento do genótipo com base na MF. 
Tabela 6. Parâmetros de adaptabilidade $\left(\beta_{1}\right)$, estabilidade $\left(\sigma_{\mathrm{d}}^{2}\right)$ e coeficiente de determinação $\left(\mathrm{R}^{2}\right)$ para rendimento de óleo de genótipos de girassol $\left(\mathrm{kg} \mathrm{ha}^{-1}\right)$, obtidos através do método de Eberhart \& Russell (1966), em 2001.

\begin{tabular}{lcccc}
\hline Genótipo & \multicolumn{4}{c}{ Rendimento de óleo $\left(\mathrm{kg} \mathrm{h}^{-1}\right)$} \\
\cline { 2 - 5 } & Média & $\beta_{1}$ & $\sigma^{2}{ }_{\mathrm{d}}$ & $\mathrm{R}^{2}$ \\
\hline AG 966 & 860 & $1,09^{\mathrm{ns}}$ & $3.057,05^{\mathrm{ns}}$ & 92,40 \\
CF 13 & 901 & $1,09^{\mathrm{ns}}$ & $-760,45^{\mathrm{ns}}$ & 97,02 \\
CF 17 & 791 & $1,08^{\mathrm{ns}}$ & $8.918,28^{* *}$ & 85,97 \\
DK 4030 & 865 & $0,89^{\mathrm{ns}}$ & $12.736,90^{* *}$ & 75,67 \\
GH 12 & 855 & $1,27^{(1)}$ & $2.115,16^{\mathrm{ns}}$ & 95,14 \\
GV 26043 & 812 & $0,89^{\mathrm{ns}}$ & $-1.950,19^{\mathrm{ns}}$ & 97,88 \\
HT 3 & 614 & $0,59^{(1)}$ & $31.732,54^{* *}$ & 38,66 \\
M 734 (T) & 821 & $0,86^{\mathrm{ns}}$ & $13.273,41^{* *}$ & 74,02 \\
MILENIO & 894 & $1,27^{(1)}$ & $14.251,54^{* *}$ & 85,40 \\
VDH 488 & 820 & $0,91^{\mathrm{ns}}$ & $8.669,51^{* *}$ & 81,43 \\
VDH 93 & 780 & $1,01^{\mathrm{ns}}$ & $4.819,55^{*}$ & 88,93 \\
\hline
\end{tabular}

${ }^{(1)}$ Significativo a $5 \%$ de probabilidade, pelo teste t. ${ }^{\text {ns }} \mathrm{Não}$-significativo. $*$ e **Significativo a 5 e $1 \%$ de probabilidade, respectivamente, pelo teste F.

ser indicado para os dois tipos de ambiente, mas apresentar diferenças na magnitude dessa superioridade. Assim, a análise de regressão pode fornecer informações sobre a resposta dos genótipos decorrente de variações ambientais.

Neste estudo, o genótipo Milênio, em 2001, apresentou rendimento de óleo 17,35\% superior à média da testemunha nos ambientes favoráveis e apenas $0,4 \%$, nos ambientes desfavoráveis, devendo ter indicação geral (Tabela 4). Contudo, a análise do coeficiente de regressão revelou que ele apresentou uma maior responsividade nos ambientes favoráveis $\left(\beta_{1}>1\right)$ (Tabela 6). Essas informações indicam que o produtor pode cultivar o genótipo Milênio na safrinha nos dois ambientes, mas que a melhoria das condições ambientais (maior adubação, adequação da época de plantio, melhor controle fitossanitário) poderá trazer retornos econômicos, pois o genótipo apresentou alta responsividade $\left(\beta_{1}>1\right)$ a essa melhoria. Por sua vez, o genótipo DK 4030 obteve indicação geral, mas com responsividade média $\left(\beta_{1}=1\right)$ a melhoria das condições ambientais. Além do coeficiente de regressão, os parâmetros $\sigma_{\mathrm{d}}^{2}$ e $\mathrm{R}^{2}$ utilizados no método de Eberhart \& Russell (1966) possibilitaram realizar avaliações de estabilidade dos genótipos, verificando as oscilações dos componentes de rendimento frente às mudanças ambientais. O genótipo Milênio, mesmo apresentando $\sigma^{2}{ }_{d}$ significativo, teve $R^{2}$ alto e, portanto, pode ser considerado estável.

\section{Conclusões}

1. Entre os métodos avaliados, a análise da decomposição da média geral em médias de ambientes favoráveis e desfavoráveis (método da IDMG) é o mais adequado para a indicação de genótipos.

2. A análise de regressão, por caracterizar a responsividade e previsibilidade dos genótipos em relação às mudanças ambientais, contribui com informações adicionais à indicação de genótipos com base no método da IDMG.

\section{Agradecimentos}

Aos pesquisadores e instituições que avaliaram os ensaios de genótipos de girassol.

\section{Referências}

ALLARD, R.W.; BRADSHAW, A.D. Implications of genotypeenvironmental interaction in applied plant breeding. Crop Science, v.4, p.503-508, 1964.

BRASIL. Ministério da Agricultura, Pecuária e Abastecimento. Disponível em: <www.agricultura.gov.br>. Acesso em: 10 jan. 2006.

CARNEIRO, P.C.S. Novas metodologias de análise de adaptabilidade e estabilidade de comportamento. 1998. 182p. Tese (Doutorado) - Universidade Federal de Viçosa, Viçosa.

CARVALHO, C.G.P. de; ALMEIDA, C.M.V.C. de; CRUZ, C.D.; MACHADO, P.F.R. Hybrid cocoa tree adaptability and yield temporal stability in Rondônia State, Brazil. Crop Breeding and Applied Biotechnology, v.3, p.237-244, 2003.

CARVALHO, C.G.P. de; ARIAS, C.A.A.; TOLEDO, J.F.F.; ALMEIDA, L.A. de; KIIHL, R.A.S.; OLIVEIRA, M.F. Adaptability and stability study of soybean lines developed for high yield in Paraná State using four methodologies. Crop Breeding and Applied Biotechnology, v.2, p.247-256, 2002.

CONAB. Acompanhamento da safra 2004/2005. Disponível em: <http://www.conab.gov.br>. Acesso em: 15 nov. 2005.

CRUZ, C.D. Programa Genes: versão Windows: aplicativo computacional em genética e estatística. Viçosa: UFV, 2001. 648p.

CRUZ, C.D.; REGAZZI, A.J. Modelos biométricos aplicados ao melhoramento genético. Viçosa: UFV, 1994. 390p.

DE LA VEGA, A.J.; CHAPMAN, S.C. Defining sunflower selection strategies for a highly heterogeneous target population of environments. Crop Science, v.46, p.136-144, 2006.

EBERHART, S.A.; RUSSELL, W.A. Stability parameters for comparing varieties. Crop Science, v.6, p.36-40, 1966.

LEITE, R.M.V.B. de C.; BRIGHENTI, A.M.; CASTRO, C. de. (Ed.). Girassol no Brasil. Londrina: Embrapa Soja, 2005. 641p.

LIN, C.S.; BINNS, M.R. A superiority measure of cultivar performance for cultivar x location data. Canadian Journal of Plant Science, v.68, p.193-198, 1988. 
LU'QUEZ, J.E.; AGUIRREZÁBAL, L.A.N.; AGÜERO, M.E.; PEREYRA, V.R. Stability and adaptability of cultivars in nonbalanced yield trials. Comparison of methods for selecting 'High Oleic' sunflower hybrids for grain yield and quality. Journal of Agronomy and Crop Science, v.188, p.225-234, 2002.
PIMENTEL-GOMES, F. Curso de estatística experimental. 11.ed. São Paulo: Nobel, 1985. 466p.

RAMALHO, M.A.P.; SANTOS, J.B. dos; ZIMMERMANN, M.J. de O. Genética quantitativa em plantas autógamas: aplicações ao melhoramento do feijoeiro. Goiânia: UFG, 1993. 271p.

$\overline{\text { Recebido em } 9 \text { de junho de } 2006 \text { e aprovado em } 12 \text { de março de } 2007}$ 